\title{
A formação continuada de professores no espaço escolar: impactos na prática docente
}

\author{
The teachers training in schools: \\ impacts in teaching practice
}

\section{Mari Margarete dos Santos Forster ${ }^{[a]}$, Carina Maria Veit ${ }^{[b]}$, Andréia Veridiana Antich ${ }^{[c]}$, Marelise de Fátima Griebeler Reis ${ }^{[d]}$}

[a] Professora Doutora titular do PPG em Educação da Universidade do Vale do Rio dos Sinos (Unisinos), Porto Alegre, RS - Brasil, e-mail: mari.forster@gmail.com

[b] Mestranda Capes/Prosup, Universidade do Vale do Rio dos Sinos (Unisinos), Novo Hamburgo, RS - Brasil, e-mail: carinamaria.veit@gmail.com

[c] Mestranda CNPq/Proex, Universidade do Vale do Rio dos Sinos (Unisinos), São Sebastião do Caí, RS Brasil, e-mail: andreiaveri@terra.com.br

[d] Mestre em Educação pela Universidade do Vale do Rio dos Sinos (Unisinos), integrante do grupo de pesquisa e supervisora da escola parceira da pesquisa, Universidade do Vale do Rio dos Sinos (Unisinos), Montenegro, RS - Brasil, e-mail: marelisereis@terra.com.br

\section{Resumo}

Este trabalho apresenta uma reflexão sobre a formação continuada dos professores, seus impactos e limites na prática docente, examinada a partir da vivência de diferentes situações formativas, no cotidiano de uma escola pública. A partir da análise de conteúdo dos 
dados oriundos de um recorte de entrevistas semiestruturadas realizadas com os professores parceiros deste estudo, algumas dimensões se destacaram, entre elas: o desejo da mudança; um forte traço de trabalho coletivo e colaborativo; objetivos comuns; qualidade da equipe diretiva; diálogo constante; ambiência de trabalho acolhedora; isso tudo, segundo as professoras, repercute em seu trabalho diário, em que atividades interdisciplinares são estimuladas e desenvolvidas; as relações com alunos e colegas são fraternas, críticas e reflexivas; o trabalho desenvolvido tem sido mais inovador, rompendo com lógicas lineares. A autonomia e a autoria, estimulada aos professores, entusiasma-os não só a socializarem seus trabalhos interna, mas externamente, e auxilia-os a compreenderem essas duas dimensões como fundantes para a prática pedagógica. O estudo tem mostrado o quanto o professor se forma na escola e, ao mesmo tempo, o quanto o professor forma a escola. As repercussões no currículo escolar são visíveis quando isso ocorre e favorecem um ensino da melhor qualidade. Mudanças ocorridas não podem ser interpretadas como somente uma consequência mecânica de uma ação instrumental da formação continuada, pois resultam de uma conjugação de fatores favoráveis, os quais necessitam ser considerados pelos formadores, pelas escolas, pelos responsáveis pelos sistemas de ensino e pelas políticas públicas.

Palavras-chave: Formação continuada. Escola. Prática docente.

\section{Abstract}

This paper presents a reflection on the continuing education of teachers, and limits its impact on teaching practice, examined from the formative experience of different situations in everyday life in a public school. From the content analysis of data from a crop of semi-structured interviews with the teachers partners in this study, some aspects are highlighted, including: the desire for change, a strong streak of collective work and collaborate, common goals; quality management team, ongoing dialogue, working cozy ambience, all of this, according to the teachers, have repercussions in their daily work where interdisciplinary activities are encouraged and developed relationships with students and colleagues are fraternal, critical and reflective, the work has been more innovative, breaking with linear logic. The autonomy and authorship stimulated teachers, enthuse them not only to socialize their work internally but externally and helps them to understand these two dimensions as fundamental to the pedagogical practice. The study has shown how 
the teacher is formed at school and at the same time, how the teacher form school. The repercussions on the school curriculum are visible when it occurs and promotes a better quality of education. Changes can not be interpreted as only a mechanical consequence of a mechanical action of continuing education, as the result of a combination of favorable factors, which need to be considered by the trainers, the schools, those responsible for education and for public policies.

Keywords: Continued education. School. Teaching practice.

\section{Introdução}

A formação continuada dos professores pode ser examinada sob diferentes prismas, este texto a analisa sob a perspectiva de professoras de uma escola pública de ensino fundamental, localizada no Sul do Brasil. Essas profissionais examinam os impactos, no seu desenvolvimento profissional, de várias situações vividas, bem como suas repercussões sobre a prática docente. É importante ressaltar que os dados aqui analisados, oriundos do recorte de entrevistas realizadas com as docentes, situam-se no âmbito de um projeto maior, intitulado "(Re)significando a escola como espaço formativo: dos diálogos com a comunidade escolar à sistematização de conhecimentos".

O diálogo e a reflexão, na perspectiva freireana, são algumas das dimensões que orientam todo o trabalho desenvolvido. Partimos do princípio que o diálogo precisa acontecer em sua radicalidade, ou seja, para além das prováveis banalizações que podem estar ocorrendo nos mundos das escolas, das salas de aula ou fora delas. A investigação procurou pautar-se pelo diálogo em sua dimensão ontológica, tomada, então, como referência para pensar a formação humana. Logo, os encontros do grupo de pesquisa com a escola ocorreram valorizando não apenas a palavra, mas o saber das pessoas, tornando a atividade investigativa um processo que faz e tem sentido para quem o vive. 
A reflexão/problematização, que aqui é entendida como a articulação recíproca entre a teoria e prática, é configurada no espaço efetivo da práxis, portanto, do conhecimento e do agir humano.

Interessa, portanto, a esta investigação a produção de conhecimentos. Logo, a reflexão e o diálogo não se reduzem a conversações ao estilo confessional entre os sujeitos envolvidos, mas sim como uma reconstrução crítica que favorece a compreensão da própria experiência individual e coletiva; os sujeitos separam-se da imediaticidade, percorrem o processo de abstrações sucessivas que se distanciam do real e a ele retornam, efetivando um mergulho em sua dinâmica concreta (TORRIGLIA, 2000). Logo, registramos, por meio do diálogo com professoras, suas reflexões sobre um currículo em ação e o quanto sua vivência pode ser impulsionadora do desenvolvimento profissional e provocadora de novas práticas. Da mesma forma, consideramos os limites e os tensionamentos identificados pelos sujeitos envolvidos ao experienciarem diferentes situações formativas.

Cautermann et al. (1999) e Fusari (1999) dizem que as repercussões da formação continuada nas práticas escolares não podem ser interpretadas de forma direta e linear. Considerando o projeto em questão como parte de um percurso formativo, sabemos, com clareza, que cada sujeito apropria-se diferentemente do vivido e que essa ação ocorre em momentos distintos, assim como o tempo necessário para proporcionar repercussões pode variar, considerando características individuais e coletivas. Conforme apontam Cauterman et al. (1999), em estudo sobre os impactos da formação continuada nas práticas docentes, a influência desta é relativa, podendo provocar mudanças substanciais e permanentes, modificações momentâneas ou, até mesmo, não ocasionar alteração alguma.

Fusari (1999) também salienta que muitos professores promovem reformulações em suas práticas independentemente da formação continuada e que não podemos afirmar que algumas mudanças realizadas no fazer pedagógico sejam realmente repercussões de um processo formativo intencional. Por outro lado, as atividades de formação são parte da vida do professor, um sujeito que, como diria Nóvoa (1992), paralelamente ao fazer docente, vive processos que influenciam seu modo de ser docente. 
Nesse contexto, as mudanças observadas nas práticas docentes e na escola não podem ser interpretadas apenas como uma consequência mecânica em reação a uma ação 'instrumental' da formação continuada. Elas resultam de uma conjugação de fatores favoráveis, os quais carecem de maior reflexão e valorização por parte dos formadores, das escolas e dos responsáveis pelos sistemas de ensino.

Quanto à metodologia do trabalho, os critérios para a escolha dos sujeitos a serem entrevistados foram definidos considerando a intenção de abarcar tanto os professores responsáveis pelos anos iniciais e os anos finais do ensino fundamental quanto os envolvidos com funções específicas de setores escolares como biblioteca e laboratório de aprendizagem, ou seja, que atendem os alunos da escola sem possuírem uma turma fixa. Dessa forma, foram selecionadas, por meio de sorteio, cinco professoras com mais de dois anos de atuação na escola referida. Para efeitos de organização do texto, usaremos os nomes Orquídea, Rosa, Hortênsia, Violeta e Margarida para representar os sujeitos do estudo.

Tendo como objetivo central compreender como percebem a contribuição das ações realizadas na escola no âmbito da formação continuada, as professoras foram convidadas a exporem suas ideias acerca dos impactos e limites em relação a elas mesmas. Os dados foram analisados considerando como eixos o trabalho coletivo, o papel da equipe diretiva, a aproximação e integração entre diferentes áreas do conhecimento, o professor como produtor de saber e a relação dialógica entre professores e entre professores e alunos. Muitos foram os pontos de convergência nas exposições, bem como as particularidades advindas dos olhares e vivências individuais.

\section{Impactos: entrecruzamentos de diferentes realidades}

As professoras entrevistadas, ao se referirem aos impactos sentidos ao viverem o currículo, trazem considerações pelo contraexemplo, tendo como referência a comparação com contextos de outros ambientes escolares onde atuam. A ausência ou o silenciamento do eixo trabalho 
coletivo que identificam em outras instituições estão explicitados na fala de Rosa, dentre outras:

era muito assim... Cada professor na sua sala de aula, cada professor fazendo seu trabalho... [...] nessa escola estadual onde fiquei 19 anos. Mas não tinha, assim, a preocupação de se trabalhar com o todo, toda uma escola envolvida no mesmo assunto, trabalhando com o mesmo objetivo. Isso, nas outras escolas não tinha. Isso é o que eu gosto; isso é que faz a diferença.

Essa afirmação assume maior vulto relacionado ao contexto da escola pesquisada, na qual são recorrentes as afirmações que envolvem a construção coletiva, seja de projetos ou de decisões relevantes. Percebe-se que a professora valoriza as ações situadas a partir de objetivos comuns e pontua o quanto "isso faz a diferença".

Podemos identificar um elemento significativo e presente nas manifestações das demais entrevistadas: a grande valorização do trabalho em parceria e a disposição para a constituição de um coletivo de trabalho no qual o conflito não é eliminado, mas discutido e negociado. Há uma ênfase no diálogo e nas tomadas de decisão coletivas, consideradas como fio condutor da gestão democrática enquanto instância que fortifica o grupo. Percebemos os resultados de um trabalho voltado para o desenvolvimento do que Pérez Gómez (2001) denomina cultura de colaboração. Esta não se estrutura de forma espontânea, necessita originar-se da vontade e da expectativa do grupo, por meio de um processo intencionalmente planejado e desenvolvido, o qual fornece suporte para as demandas do cotidiano e repercute na melhoria das relações escolares e de aprendizagem.

O destaque da diferença dessa escola em relação a outras, nas quais o individualismo é preponderante, indica o reconhecimento dos ganhos do trabalho em parceria. Sentir-se parte, receber apoio, dar apoio e perceber-se sujeito de um percurso coletivo de formação focado em um trabalho conjunto com vistas à aprendizagem tem sido marcadamente estimulante. Contudo, é preciso entender a construção coletiva no interior da escola como um processo que exige a produção de algumas condições capazes de possibilitar essa interação. 
Nessa direção, observam-se mudanças nas práticas docentes orientadas a um trabalho mais integrado entre os componentes curriculares. Situação essa que vem sendo articulada, principalmente, por projetos coletivos, ${ }^{1}$ envolvendo a escola como um todo e perpassando as diferentes áreas do conhecimento.

A definição de uma estratégia comum, a qual necessita do trabalho coletivo para se realizar e se assenta na busca de soluções para um problema consensual, parece ter sido o ponto forte dos projetos. Houve, por parte dos alunos, uma participação marcada pelo entusiasmo e pela curiosidade, contagiando os professores, que, inicialmente, estavam cautelosos em relação à proposta e fazendo-os aderir a ela de forma mais confiante. Além disso, também foi possível identificar o fortalecimento do sentimento de pertença ao grupo em todos os segmentos da comunidade escolar.

Esse é um indicador de mudança nas práticas educativas da escola, que, conforme sinaliza Nóvoa (1992, p. 28), precisa ser pensada a partir de duas perspectivas, as "escolas não podem mudar sem o empenhamento dos professores; e estes não podem mudar sem uma transformação das instituições em que trabalham". Embora a inovação dependa dos professores, sem mudar o contexto em que esses atuam não haverá esforço que sustente qualquer tentativa de inovação.

Nesse caso em específico, a escola está mudando paralelamente e em decorrência do trabalho dos professores, articulado com e pela equipe diretiva nos encontros de formação e nas diferentes dinâmicas do cotidiano escolar, estimulando um repensar constante da comunidade escolar. Embora a equipe diretiva saliente que cada professor tem liberdade para aderir ou não aos projetos coletivos da escola, percebe-se, em grande número, a vontade e o entusiasmo em participar, mesmo que essas atividades demandem maior carga horária de trabalho e envolvimento intelectual do professor com seu fazer. Rios (2005, p. 127) colabora com a reflexão ao apontar que:

1 O tema do projeto de 2007 e 2008 foi “É possível uma sociedade justa?"; em 2009: “A humanidade tem fome de quê? O que de fato precisamos para viver?". E, agora, 2010: "É preciso saber viver? O que precisamos saber para cuidar da vida?". 
um projeto de escola não se faz sem a participação de todos os que a constituem e não é mera soma de projetos individuais, mas sim uma proposta orgânica, em que se configura a escola necessária e desejada, e na qual se articulam, na sua especificidade, as ações de cada sujeito envolvido.

$\mathrm{Na}$ escola pesquisada, as mudanças estão articuladas entre si e ao projeto coletivo, o qual apresenta uma concepção de educação e de 'escola desejada', conforme menciona Rios, reforçando a compreensão de que há objetivos comuns e um projeto pedagógico em movimento. Para Cunha (1998, p. 109),

o trabalho coletivo reforça a possibilidade de êxito das iniciativas individuais através da possibilidade de partilha, da troca de experiência, da reflexão conjunta e realimenta a disposição do professor que se dispõe a fazer ruptura com a prática pedagógica dominante.

A visão da escola como um espaço colaborativo, em que o trabalho dos diferentes profissionais essenciais ao fazer educativo articula-se, é apontada por várias educadoras e pode ser representada por essa fala de Rosa: "a escola não é a direção, não são os alunos, somos todos nós". Ela enfatiza a qualidade do trabalho da equipe diretiva, cujo reconhecimento aparece, igualmente, na manifestação de outras educadoras.

Desde que eu estou aqui e encontrei essa equipe diretiva, é muito bom de se trabalhar [...] Eu creio que pela diretora ter sido professora durante muitos anos, quando tu falas de alguma necessidade da tua de sala de aula, de alguma preocupação tua, tens um retorno, sabe?! É uma coisa, assim, quase imediata. Nas outras escolas era mais lento e esse 'mais lento' ia truncando o teu trabalho.

O destaque para a equipe diretiva, extremamente participativa e atuante - composta por diretora, vice-diretora, supervisora escolar e orientadora pedagógica -, é recorrente na fala das professoras. Equipe essa que desempenha os papéis de apoio ao fazer pedagógico de cada professor, articula o trabalho conjunto e coordena o processo de formação 
continuada. Isso é favorecido pelo fato de a formação em processo de trabalho ser compreendida como um percurso de atendimento das necessidades coletivas, mas também das individuais. Valoriza-se o coletivo enquanto espaço de interaprendizagem e de articulação dos trabalhos individuais e o individual pelo entendimento de que cada professor prescinde de um acompanhamento sobre as suas dificuldades específicas, princípios da proposta de formação adotada pelo projeto de formação continuada em estudo.

Essas professoras consideram, portanto, a escola como um espaço constituído poreio de uma 'proposta orgânica', como aponta Rios (2005). Nela, a interação é premissa do trabalho docente que:

não consiste apenas em cumprir e executar, mas também é uma atividade de pessoas que não podem trabalhar sem dar um sentido ao que fazem, é uma interação com outras pessoas: os alunos, os colegas, os pais, os dirigentes da escola, etc. (TARDIF; LESSARD, 2005, p. 38).

Outra questão parece perpassar a do trabalho coletivo, na fala de Violeta: os impactos ampliam-se para além da relação entre os colegas e chegam à sala de aula, por meio das possibilidades de trocas entre as áreas e as disciplinas. Considerando a ideia de Freire e Shor (2006, p. 19) de que "a educação deve ser integradora - integrando os estudantes e os professores numa criação e re-criação do conhecimento comumente partilhadas", podemos observar, no dizer da professora, o quanto o trabalho coletivo pode ajudar a escola a transpor fronteiras entre as diferentes áreas do conhecimento.

Entrelaçado ao trabalho coletivo e às aproximações entre as áreas do conhecimento, o diálogo revela-se como outro elemento em destaque: "o principal, que eu diria e que como começou o nosso trabalho aqui, é ter esse momento, o espaço de sentar e conversar... a gente não tem, em outros lugares, esse espaço" (Orquídea). Percebe-se que ela afirma serem esses momentos o começo da trajetória de trabalho coletivo da instituição, destacando, ao mesmo tempo, que eles não se fazem presentes em outros ambientes. A professora parece atribuir à possibilidade de 'sentar e conversar' o fundamento do trabalho diferenciado da escola pesquisada, reconhecendo-a 
como um espaço formativo, por meio do diálogo, das trocas entre colegas e dos momentos oferecidos para o encontro.

Nesse sentido, cabe ressaltar que a formação centrada na escola é o eixo buscado pelo projeto de pesquisa e formação no qual a escola em estudo está envolvida. Por meio das manifestações das professoras entrevistadas, é possível identificar avanços não só na articulação do coletivo, mas, sobretudo, na constituição de uma concepção de professores e equipe diretiva como produtores de saberes e protagonistas de sua própria formação.

Orquídea destaca, ainda, a aprendizagem que realiza com seus alunos e colegas:

esses momentos em que a gente se reúne, [...] essa troca de ideias que a gente faz do meu trabalho, do que eu estou fazendo na minha aula, do que o outro colega está fazendo, [...] eu acho que esse é o melhor momento que a gente tem, porque tu aprendes com o teu colega, tu aprendes com a experiência que o teu aluno traz e, nesses momentos em que a gente pode socializar isso, em que a gente pode trocar essa ideia, acho que é o melhor momento de formação que a gente tem.

No tocante à socialização de saberes propiciada pelas atividades de formação em serviço, em estudos sobre os saberes docentes, Tardif (2002) menciona que professores a veem como um fator de crescimento profissional. Reconhecimento corroborado por Ghauthier (1998), o qual, assim como Tardif (2002, p. 52), entende que é "através das relações com os pares e, portanto, do confronto entre saberes produzidos pela experiência coletiva dos professores, que os saberes experienciais adquirem certa objetividade", proporcionando aos professores da escola básica maior confiança em sua competência e a possibilidade de serem reconhecidos por outros grupos profissionais.

De acordo com os dados, a experiência profissional constitui fonte de aprendizagem sobre o trabalho docente, assim como subsídio para o enfrentamento das dificuldades surgidas no dia a dia. A formação continuada é valorizada pelas participantes deste estudo enquanto 
espaço de troca, sobretudo quando é garantida e reconhecida como espaço institucional e ocorre no lócus da escola.

A afirmação acima parece ainda mais interessante quando alinhada aos relatos sobre outras vivências dessas professoras. Observemos o dizer de Rosa:

mas, assim, em relação ao ambiente de trabalho, ele é muito bom, sabes? Porque eu vim de uma escola, eu até comentei com as gurias... O primeiro dia em que eu cheguei numa escola aqui do município tinha um local que as professoras do currículo sentavam e as de área, em outro. E eu, desavisada, sentei ali. Prontamente, disseram: "não! Aí senta o pessoal da área!". Isso não existe aqui [...] Mas é muito gostoso de trabalhar aqui. E isso é muito bom.

Para além de discutir possíveis questões de poder existentes na escola, interessa-nos refletir sobre o comparativo feito pela professora. Ela traz, como um possível resultado da presença do diálogo e da interação, um apreço pelo ambiente da escola pesquisada, o que se traduz no gosto pelo trabalho. Conforme Tardif e Lessard (2005, p. 53), "se a experiência de cada docente que encontramos é bem própria, ela não deixa de ser também a de uma coletividade que partilha o mesmo universo de trabalho, com todos os desafios e suas condições”. Assim, o espaço escolar e as relações nele implicadas podem influenciar o fazer docente. Penin (2008, p. 649) vai além e aponta que:

a vivência de uma profissão, de uma instituição e principalmente de um cotidiano com um grupo de pares e outras pessoas que o constituem (no caso do professor, uma escola, os alunos e seus pais, os servidores, a comunidade, os representantes e superiores da instituição etc.) geralmente interfere de maneira vigorosa no desenvolvimento da própria identidade ou "identidade do eu".

Outro aspecto relevante é destacado por Margarida ao referir-se à relação dos professores com os estudantes e com o seu próprio trabalho. No seu dizer: 
o pensar no aluno é diferente, a maneira de agir com os alunos é diferente, o ficar dentro da sala de aula é diferente, aqui a gente não deixa nunca uma turma sozinha.

Traçando um paralelo com outros espaços que conhece, ela articulou esse posicionamento à vontade e ao entusiasmo dos colegas em relação ao projeto de formação docente vivenciado na escola e ao seu próprio trabalho. Ela parece dizer que a forma como os professores veem os jovens tende para uma percepção mais abrangente e que a relação com os alunos é muito boa. Na comparação com outra escola em que atua, associa o 'ficar dentro da sala de aula' com algo agradável, assim como destaca o comprometimento dos demais educadores com o trabalho docente e com a aprendizagem.

Essa percepção também aparece no depoimento de Rosa quando comenta sobre a preocupação com os alunos e com um processo educativo que contemple as suas necessidades e as suas potencialidades, como ocorre na escola pesquisada:

nas outras escolas não era assim; era tudo muito tradicional sabes: testes, seguir aquilo que estava no plano de curso e não levava muito em conta os conhecimentos/saberes prévios dos alunos. E aqui não, aqui já tem essa preocupação, sabes, com o aluno, com o educando, essa liberdade que a diretora nos dá de tu ires com teu aluno até onde tu sabes que ele pode ir.

Orquídea salientou que o processo de formação oportunizado pela escola provocou mudanças em sua forma de lidar com o seu trabalho e que isso repercutiu não somente nessa escola, mas, também, em outra na qual trabalha. Isso mostra que os impactos da formação podem ir além de uma situação determinada, acompanhando a vida desses sujeitos. Conforme destaca a professora a seguir:

[...] nas minhas aulas, mesmo na outra escola, eu não consigo trabalhar como eu trabalhava antes... então todo esse trabalho que eu faço aqui, que mudou meu comportamento aqui, eu levo pra dentro da minha sala de aula, eu posso não levar pra outra escola, mas pras minhas aulas eu levo (ORQUÍDEA, grifos nossos). 
Essa manifestação encontra eco nos estudos de Cauterman et al. (1999), em que alguns professores expressaram que, ao serem mobilizados por atividades de continuidade da formação, se sentiram impulsionados a promover mudanças permanentes na prática. Portanto, para onde forem, levarão consigo uma nova visão sobre o fazer docente e sobre o seu papel, podendo influenciar os outros contextos e pessoas com as quais convivam. Podemos, assim, inferir que o clima organizacional pode atuar como um condicionador de ações inovadoras, favorecendo ou limitando iniciativas individuais ou coletivas.

\section{Alguns limites: repensando o percurso}

Paralelamente ao conhecimento dos impactos da formação continuada, instigamos sugestões, com vistas a definir possibilidades de qualificar o percurso formativo do qual são parte e, também, identificar elementos percebidos enquanto limitadores do processo. As sugestões dos professores centraram-se em: ampliação de espaço e de tempo para planejamento e troca de experiências, socialização de possibilidades metodológicas e atividades práticas e adequação e melhoria nos recursos físicos e humanos da escola.

Hortênsia indica sentir falta de trocas de sugestões que oportunizem acréscimos no seu repertório de atividades práticas. Parece solicitar um "roteiro a ser seguido", com certa indiferença aos processos reflexivos desenvolvidos no cotidiano escolar. Essa é uma questão que se repete na fala de Margarida, que, apesar de valorizar a reflexão na formação e verbalizar o sentimento de que se não participasse desse processo e não estivesse nessa escola "seria uma pessoa mais apática", diz:

um curso de professores deveria trazer sugestões de atividades, coisas diversas, coisas diferenciadas, maneiras de ensinar determinados assuntos; isso eu acho que contribui realmente para a tua prática ser melhor. 
A solicitação de que sejam apresentadas atividades diferenciadas não pode ser compreendida somente como uma visão instrumental da formação, pois o conhecimento contribui para os professores visualizarem propostas que rompam com o paradigma tradicional de ensino, vindo a atender às necessidades e expectativas de seus alunos.

A maior parte das entrevistadas valoriza esse espaço-tempo e gostaria de desenvolver atividades inerentes à tarefa docente dentro da formação, tal como apresenta Margarida:

eu sinto que o professor deveria ter mais tempo disponível para conversar, para ter ideias de trabalhos, para ter ideias de atividades, para ter ideias de projetos [...] sentar junto, conversar e elaborar atividades e elaborar a aula em si [...].

Ampliar o repertório de propostas e atividades pedagógicas realmente implica ter tempo para investigação, elaboração e reflexão e não pode ser interpretado no plano do ativismo. Contudo, considerando a carga horária de trabalho em sala de aula, esse aspecto do trabalho docente, ou seja, o planejamento, tem sua realização inviabilizada nesse espaço.

Orquídea solicita tempo para planejar, pois entende que nas situações nas quais isso ocorre "sai coisa muito boa", mostrando o reconhecimento da qualidade do trabalho por elas realizado na escola quando são oferecidas condições.

Violeta direciona sua sugestão para a atualização de conhecimentos específicos e para a necessidade de maior número de profissionais de apoio ao fazer pedagógico, mostrando o quanto a falta de estrutura interfere na qualidade do trabalho docente. Sua manifestação deixa isso claro:

eu acho que a gente tem de se atualizar, procurar fazer cursos e coisas na área em que a gente está [...]. O que a escola sente bastante dificuldade é em relação aos recursos humanos, que, no ano passado, tinha mais. Tinha mais pessoas para substituir ou quando acontecem essas coisas assim, sempre, 
todos os professores que estão na informática, na biblioteca, têm de fechar tudo para ir para a sala de aula para substituir a gente.

Esses são elementos considerados fatores de restrição da participação dos professores em atividades de formação continuada, muito embora a LDB 9.394/96 contemple o afastamento para atividades de formação continuada nos artigos 63 e 67, prevendo, inclusive, a manutenção da remuneração. Como fator limitante, deixa a cargo dos sistemas de ensino essa prerrogativa, os quais não vêm desenvolvendo uma estrutura que dê conta das implicações da saída dos professores.

Reconhecendo-se como produtora de saberes, Rosa diz que gostaria que tudo continuasse da mesma forma, mantendo as oportunidades de troca de saberes experienciais e ensinando e aprendendo com a parceria entre universidade e escola. Ela ainda salienta a importância do projeto de formação para a manutenção do qualificado ritmo de trabalho na escola.

Eu quero que continue, sabem, gurias, porque, às vezes, tu vês, até na vida pessoal, às vezes, a gente que começa 'quero fazer isso' e daqui a pouco vai morrendo aquela coisa lentamente. Que bom que a escola começou com um pique e que ela continua com esse pique, sabe? [...] Eu quero mais é [...] ter espaço de troca, que vocês venham, que a gente possa ir até vocês também. Isso é muito bom, tanto para vocês, creio, como para nós, também é muito bom. [...] A gente a cada dia está construindo conhecimento, cada reunião que vem, uma simples mensagem que tem ali, tudo, tudo, tudo te faz pensar, refletir sobre a tua prática. Então, eu só quero que continue, foi muito bom, foi muito bom! [...] Quero mais é que continue, quero mais é ver vocês aqui muito tempo (risadas).

Essa fala aponta um indicador significativo acerca das aprendizagens, advindas das atividades propostas na escola, que culminam com a construção de novos conhecimentos. Outro aspecto presente é o desejo de continuidade do diálogo entre a universidade e a escola a partir do qual ela identifica a produção de saberes e o exercício da reflexão sobre a própria prática. 


\section{À guisa de conclusão}

No entendimento da maior parte das professoras, a formação desenvolvida atende às necessidades particulares dos professores e da escola como um todo, articulando os percursos formativos individuais com o desenvolvimento do coletivo escolar.

No tocante aos avanços observados, podemos dizer que as relações com os colegas professores são consideradas satisfatórias e, com os alunos, percebidas como mais prazerosas, gerando a vontade de estar em sala de aula. A maneira como veem as crianças e os adolescentes e a compreensão de que aprendem com eles parece favorecer a constituição de uma forma mais qualificada de convívio. O desenvolvimento dos alunos dessa escola é satisfatório e o envolvimento com os projetos coletivos é grande.

O trabalho coletivo, a troca de experiências, o apoio diante das dificuldades e a inovação por meio dos projetos integradores são facilitados pela existência da relação formativa estabelecida no contexto analisado. O trabalho escolar desenvolvido em uma perspectiva interativa, considerando tanto os saberes e as necessidades dos professores quanto às perspectivas e interesses dos alunos como ponto de partida, provoca maior envolvimento de todos nas dinâmicas da escola, que passa a fortalecer o sentimento de pertença nos sujeitos envolvidos.

A autonomia e a autoria, estimuladas aos professores, entusiasmam estes não só a socializarem seus trabalhos interna e externamente, mas os auxiliam a compreenderem essas duas dimensões como fundantes para a prática pedagógica. O estudo tem mostrado o quanto o professor se forma na escola e, ao mesmo tempo, o quanto o professor forma a escola. As repercussões no currículo escolar são visíveis quando isso ocorre e favorecem um ensino da melhor qualidade. Mudanças ocorridas não podem ser interpretadas como somente uma consequência mecânica de uma ação instrumental da formação continuada, pois resultam de uma conjugação de fatores favoráveis, os quais necessitam ser considerados pelos formadores, pelas escolas, pelos responsáveis pelos sistemas de 
ensino e pelas políticas públicas. Acreditamos ter contribuído, com esse estudo, na necessária reflexão sobre aspectos desse processo.

\section{Referências}

BRASIL. Lei n. 9.394/96, de 20 de dezembro de 1996. Estabelece as diretrizes e bases da educação nacional. Diário Oficial [da] República Federativa do Brasil, Poder Legislativo, Brasília, DF, 23 dez. 1996. p. 27833. Disponível em: <http://www6.senado.gov.br/legislacao/ListaTextoIntegral.action?id=75723 >. Acesso em: 23 jul. 2009.

CAUTERMAN, M-M. et al. É útil a formação contínua de professores? Porto: Rés Editora, 1999.

CUNHA, M. I. da C. 0 professor universitário na transição de paradigmas. Araraquara: JM Editora, 1998.

FUSARI, J. C. Avaliação de modalidades convencionais e alternativas de educação contínua de educadores: preocupações a serem consideradas. In: BICUDO, M. A. V.; SILVA Jr., C. A. da (Org.). Formação do educador e avaliação educacional: formação inicial e contínua. São Paulo: UNESP, 1999. p. 221-224. (Seminários e debates).

FREIRE, P.; SHOR, I. Medo e ousadia, o cotidiano do professor. 11. ed. São Paulo: Paz e Terra, 2006.

GAUTHIER, C. Por uma teoria da pedagogia: pesquisas contemporâneas sobre o saber docente. Ijuí: Ed. UNIJUí, 1998.

NÓVOA, A. Os professores e a sua formação. Lisboa: Dom Quixote, 1992.

PENIN, S. T. de S. Profissionalidade: o embate entre o concebido e o vivido. In: EGGERT, E. (Org.). Trajetórias e processos de ensinar e aprender: didática e formação de professores: livro 1. Porto Alegre: EDIPUCRS, 2008. p. 646-662.

PEREZ GOMES, A. I. A cultura escolar na sociedade neoliberal. Porto Alegre: Artmed, 2001. 
RIOS, T. A. Compreender e ensinar: por uma docência da melhor qualidade. São Paulo: Cortez, 2005.

TARDIF, M. Saberes docentes e formação profissional. Petrópolis: Vozes, 2002. TARDIF, M.; LESSARD, C. 0 trabalho docente. Petrópolis: Vozes, 2005.

TORRIGLIA, P. L. A democracia neopragmática de Rorty: algumas reflexões não-pragmáticas em relação à formação de educadores. In: SEMINÁRIO DE PESQUISA E EDUCAÇÃO DA REGIÃO SUL, 3., 2000, Porto Alegre. Anais... Porto Alegre: SPERS, 2000.

Recebido: 04/08/2010

Received: 08/04/2010

Aprovado: 08/11/2010

Approved: 11/08/2010 